\title{
Impact of Untimely Access to Formal Care on Costs and Quality of Life in Community Dwelling People with Dementia
}

Citation for published version (APA):

Janssen, N., Handels, R. L., Skoldunger, A., Woods, B., Jelley, H., Edwards, R. T., Orrell, M., Selbaek, G., Rosvik, J., Goncalves-Pereira, M., Marques, M. J., Zanetti, O., Portolani, E., Irving, K., Hopper, L., Meyer, G., Bieber, A., Stephan, A., Kerpershoek, L., ... ActifCare Consortium (2018). Impact of Untimely Access to Formal Care on Costs and Quality of Life in Community Dwelling People with Dementia. Journal of Alzheimer's Disease, 66(3), 1165-1174. https://doi.org/10.3233/JAD-180531

Document status and date:

Published: 01/01/2018

DOI:

10.3233/JAD-180531

Document Version:

Publisher's PDF, also known as Version of record

Document license:

Taverne

Please check the document version of this publication:

- A submitted manuscript is the version of the article upon submission and before peer-review. There can be important differences between the submitted version and the official published version of record.

People interested in the research are advised to contact the author for the final version of the publication, or visit the DOI to the publisher's website.

- The final author version and the galley proof are versions of the publication after peer review.

- The final published version features the final layout of the paper including the volume, issue and page numbers.

Link to publication

\footnotetext{
General rights rights.

- You may freely distribute the URL identifying the publication in the public portal. please follow below link for the End User Agreement:

www.umlib.nl/taverne-license

Take down policy

If you believe that this document breaches copyright please contact us at:

repository@maastrichtuniversity.nl

providing details and we will investigate your claim.
}

Copyright and moral rights for the publications made accessible in the public portal are retained by the authors and/or other copyright owners and it is a condition of accessing publications that users recognise and abide by the legal requirements associated with these

- Users may download and print one copy of any publication from the public portal for the purpose of private study or research.

- You may not further distribute the material or use it for any profit-making activity or commercial gain

If the publication is distributed under the terms of Article 25fa of the Dutch Copyright Act, indicated by the "Taverne" license above, 


\title{
Impact of Untimely Access to Formal Care on Costs and Quality of Life in Community Dwelling People with Dementia
}

\author{
Niels Janssen ${ }^{\mathrm{a}, *}$, Ron L. Handels ${ }^{\mathrm{a}, \mathrm{b}}$, Anders Sköldunger ${ }^{\mathrm{b}}$, Bob Woods ${ }^{\mathrm{c}}$, Hannah Jelley ${ }^{\mathrm{c}}$, \\ Rhiannon Tudor Edwards ${ }^{\mathrm{d}}$, Martin Orrelle ${ }^{\mathrm{e}}$, Geir Selbæk ${ }^{\mathrm{f}}$, Janne Røsvik ${ }^{\mathrm{f}}$, \\ Manuel Gonçalves-Pereira ${ }^{\mathrm{g}}$, Maria J. Marques ${ }^{\mathrm{g}}$, Orazio Zanetti ${ }^{\mathrm{h}}$, Elisa Portolani ${ }^{\mathrm{h}}$, Kate Irving ${ }^{\mathrm{i}}$, \\ Louise Hopper $^{\mathrm{i}}$, Gabriele Meyer ${ }^{\mathrm{j}}$, Anja Bieber ${ }^{\mathrm{j}}$, Astrid Stephan ${ }^{\mathrm{j}}$, Liselot Kerpershoek ${ }^{\mathrm{a}}$, \\ Claire A.G. Wolfs ${ }^{\mathrm{a}}$, Marjolein E. de Vugt ${ }^{\mathrm{a}}$, Frans R.J. Verhey ${ }^{\mathrm{a}}$, Anders Wimo ${ }^{\mathrm{b}}$ \\ and Actifcare Consortium \\ ${ }^{a}$ Department of Psychiatry and Neuropsychology, School for Mental Health and Neuroscience, Alzheimer Center \\ Limburg, Maastricht University Medical Center, Maastricht, The Netherlands \\ ${ }^{\mathrm{b}}$ Department of Neurobiology, Care sciences and Society, Karolinska Institutet, Stockholm, Sweden \\ ${ }^{\mathrm{c}}$ Dementia Services Development Centre, Bangor University, Bangor, UK \\ ${ }^{\mathrm{d}}$ Centre for Health Economics and Medicines Evaluation (CHEME), Bangor University, Bangor, UK \\ ${ }^{\mathrm{e}}$ Nottingham University, Institute of Mental Health, Nottingham, UK \\ ${ }^{\mathrm{f}}$ Norwegian National Advisory Unit on Ageing and Health, Vestfold Hospital Trust, Tønsberg, Norway \\ ${ }^{\mathrm{g}}$ CEDOC, Nova Medical School/Faculdade de Ciências Médicas, Universidade Nova de Lisboa, Lisbon, Portugal \\ ${ }^{\mathrm{h}}$ Alzheimer's Research Unit-Memory Clinic - IRCCS Centro S.Giovanni di Dio Fatebenefratelli, Brescia, Italy \\ ${ }^{\mathrm{i}}$ School of Nursing and Human Sciences, Dublin City University, Dublin, Ireland \\ ${ }^{\mathrm{j}}$ Martin Luther University Halle-Wittenberg, Medical Faculty, Institute of Health and Nursing Sciences, Halle, \\ Germany
}

Accepted 19 September 2018

\begin{abstract}
.
Background: Access to formal care is not always timely and a better understanding on the impact of untimely access is needed.

Objective: To examine, from a societal perspective, the impact of untimely access to formal care in terms of total costs and quality of life over one year in community dwelling people with dementia.

Methods: Within the Actifcare study, needs, resource use, and quality of life were observed for one year in a cohort of 451 community dwelling people with dementia in 8 European countries. Untimely access to care was operationalized as having at least one unmet need for care identified by the Camberwell Assessment of Need for the Elderly (CANE) instrument. Two regression models were built for both total costs and quality of life measured by the EQ-5D-5L, one using sum of unmet needs and one using a predefined selection of need items.

Results: Unmet needs were not associated with higher total costs but they were associated with a lower quality of life of people with dementia. Of all CANE items, only an unmet need for "company" was significantly related to lower total costs.
\end{abstract}

${ }^{*}$ Correspondence to: Niels Janssen, MSc, Alzheimer Centre Limburg, Maastricht University, P.O. Box 616, 6200 MD $\overline{\text { Maastricht, The Netherlands. E-mail: niels.janssen@maastricht }}$ university.nl. 
Conclusion: Total costs did not seem to differ between participants with unmet and met needs. Only few associations between specific unmet needs and costs and quality of life were found. Furthermore, quality of life of people with dementia decreases when multiple unmet needs are experienced, indicating that assessing and meeting needs is important to improve quality of life.

Keywords: Access to care, costs, dementia, quality of life, unmet needs, untimely

\section{INTRODUCTION}

Dementia has a large impact on societies and the total worldwide costs were estimated $\$ 818$ billion [1]. With increasing dependency alongside the progressive disorder, the need for unpaid informal care by family members increases [2], starting from some help in day-to-day activities to around-theclock care and supervision. Formal care services are often needed to complement the informal caregiver in order to reduce caregiver stress and burden $[2,3]$ and maintain or improve the wellbeing of the person with dementia and support the informal caregiver. Several barriers for access to and utilization of formal care exist [2,4-7] and potentially could result in a situation in which a need for formal care is unmet.

Several studies have shown negative associations between higher levels of needs and quality of life in people with dementia [8-10]. Experiencing unmet needs in day-to-day activities may also increase the risk of institutionalization as the decreasing functioning of the person with dementia poses challenges with meeting and managing increasing needs such as eating and toileting [11].

Not all care is unavoidable. Rudolph et al. [12] found that experiencing falls is an important risk factor for avoidable hospitalization, which could have been prevented by, for example, home safety improvements. Together with literature on the association between unmet needs and quality of life, this suggests that untimely access to formal care could be associated with both lower quality of life and higher consequential costs. This care, which could be formal or informal, could have been prevented or reduced if the care to meet such needs was introduced in a timely manner.

From a health-economics perspective, it is of interest to examine the impact of unmet needs in terms of care costs and generic health-related quality of life (HRQoL). This could indicate the potential for interventions targeting the prevention or reduction of unmet needs and help policy makers to distribute available resources most effectively.
A better understanding of the relationship between HRQoL, care costs, and untimely access could indicate the importance of timeliness of care. This could guide the development of interventions for improving HRQoL of community dwelling people with dementia and managing care costs. This study therefore aims to explore the impact of untimely access.

\section{METHODS}

The ACcess to TImely Formal care study (Actifcare) includes a one-year longitudinal cohort study following persons with dementia, and their informal caregivers, from eight European countries, with measures taken at baseline, six and twelve months. A detailed description can be found elsewhere [13].

\section{Participants}

In total, 451 community dwelling people with a diagnosis of mild to moderate dementia and their informal caregivers participated at baseline. Participants were eligible if they were not using regular assistance concerning personal (formal) care related to their dementia (e.g., help with washing), but were expected to start using formal care within one year and did have a Clinical Dementia Rating (CDR) of 1 or 2 (indicating mild or moderate dementia) or Mini-Mental State Examination (MMSE) $\leq 24$. All other eligibility criteria are described in detail elsewhere [13]. In each country ethical approval was obtained separately, and written informed consent was obtained for both the person with dementia and the caregiver.

For the current study, participants were eligible for analyses if at least one follow-up measurement was available. In the instance that one of the two follow up measurements was completely missing, this measurement was excluded from analyses. A follow-up measurement was considered completely missing if the assessment of care use and HRQoL could not be performed. 


\section{Measures}

The needs of the persons with dementia were derived from the Camberwell Assessment of Need for the Elderly (CANE) instrument [14]. This measure consists of 24 items relating to the person with dementia, and two relating to the informal caregiver. Each item was scored as either having no need, a met need or an unmet need. Rater (interviewer) scorings were used, which take into account both the informal caregiver and the person with dementia perspective, together with any other available information. The concept of untimely access to care was operationalized using the CANE instrument. Having an unmet need was considered untimely access to care and having a met need as timely access to care. Needs might be met by input from an informal caregiver, or from a formal care service or from both. Informal caregiver-need related items were not used in the current analyses since the focus was on the needs relating to the person with dementia.

Generic HRQoL of the person with dementia was measured using the proxy-rated EQ-5D-5L [15], which measures HRQoL in five domains including mobility, self-care, usual activities, pain/discomfort, and anxiety/depression. Every domain is scored on a five-level scale ranging from no problems to being unable or having extreme problems. These scores were transformed into utilities using UK index values $[16,17]$.

\section{Measurement of resource use and source of unit costs}

Costs were measured from a societal perspective. The Resource Utilization in Dementia (RUD) instrument [18] was used to collect data on type and frequency of resource use from both the person with dementia and the informal caregiver. Participants were asked to fill out resource use for the past 30 days at baseline and for the past six months (since the last visit) at six and twelve months, except for informal care, which asked about the last 30 days at each measurement point.

To calculate the resource use related costs, quantities of resource use were multiplied with unit prices. By necessity in this study, the recall period differed between the items. All resource use quantities were rescaled to the same period and subsequently transformed to a 1-year period to enable analyses on total costs across all observations.
Country specific unit prices (Supplementary Table 1) were obtained from various international and national sources and all prices were transformed to Euros and to 2015 values using annual exchange rates and Harmonized Indices of Consumer Prices from http://ec.europa.eu/eurostat. Unit prices were averaged and applied to all countries (Supplementary Table 1). Informal care was valued according to the opportunity cost, of which the hourly cost was reflected by the average wage derived from http://ec.europa.eu/eurostat. To reflect the mix of retired and non-retired informal caregivers, $35 \%$ of the country specific average wage was used [19].

For the current study a total cost variable was constructed, comprising both the person with dementiarelated care costs and the informal caregiver-related care costs as identified by the RUD instrument.

\section{Analyses}

Analyses were performed in the statistical software package Stata version 13 (StataCorp, TX). Baseline demographic characteristics, baseline HRQoL and needs over time were described using descriptive statistics.

The impact of untimely access to care on care costs and HRQoL were examined in two steps. First, total rescaled annual costs and HRQoL were predicted using the sum score counting the number of unmet needs among all 24 needs in a regression analysis. Second, the associations between costs and the 24 CANE items, and HRQoL and the 24 CANE items were assessed in two separate multivariate regression analyses using an automated backward procedure. CANE items were dummy coded ('no need' or 'unmet need', the reference category was 'met need') and selected if: 1) the prevalence of unmet needs was $\geq 5 \%$ at baseline and 2) dummy pair showed to be significant in univariate regression analyses based on F-tests for multiple imputed datasets to test the joint effect of each dummy pair using a cutoff $p<0.05$. Each univariate significant CANE item dummy pair was incorporated and removed if not significant ( $p \geq 0.05$; based on same test as in univariate analyses) in a backward procedure, starting with the least significant. In all regression analyses (univariate and multivariate), country and participant were used as random intercepts.

The distribution of total annual costs on imputed data was skewed (skewness factor was 5.01). They were $\log$ transformed to obtain a distribution with a skewness factor of zero by using $\ln (\operatorname{costs}+2186)$. 
Outliers on total annual costs were defined as 4 times the median absolute deviation and were omitted from analyses and descriptive statistics.

For the calculation of costs, frequencies of resource use volumes were imputed across the entire dataset by multiple imputation using the Stata 13 chained equations and predictive mean matching command to construct an imputation model with age and gender of both the person with dementia and informal caregiver, MMSE, Instrumental Activities of Daily Living, Physical Self Maintenance Scale and Neuropsychiatric Inventory, CANE, quality of life as well as RUD items as predictor variables. Ten imputed datasets were generated [20].

\section{Sensitivity analysis}

Different scenarios were tested examining robustness of results. First, the analyses on both total costs and HRQoL were rerun including any omitted outliers and performed by means of the same backwards procedure as the main analyses. Second, instead of EQ-5D-5L utilities, ICECAP-O [21] utilities were used, which focus on wellbeing instead of health, and consists of five attributes: attachment, security, role, enjoyment, and control. Scores were transformed into utilities ranging from 0 (no capability) to 1 (full capability) using the UK tariff [21]. Franklin et al. [22] showed that the ICECAP-O provides complementary information next to the EQ-5D (3L), as not all domains of health (mobility and pain/discomfort) did show a significant relationship with capabilities of ICECAP-O. To assess the overlap between ICECAP$\mathrm{O}$ and EQ-5D-5L, the correlation between their utility scores was estimated. Third, instead of including country as the random intercept, the region (Northern, Western, and Southern Europe) was used as fixed effect in regression analyses. Finally, a multivariate regression model was fitted to the change in costs and to the change in HRQoL between baseline and 12 months' follow-up, leaving 6 months' follow-up out. Independent variables comprised dummy coded clustered transitions based on having no need, unmet or met need at 12 months follow-up. For this fixed model the baseline level of need was not taken into account as the emphasis was on the level of need at 12 months.

\section{RESULTS}

Of all 451 participants, 52 (12\%) participants were excluded because they were defined as a complete loss to follow-up, leaving the data from 399 participants for the current analysis. Of these 399 participants, 10 participants had complete missing data at 6 months and 42 participants had complete missing data at 12 months, partly due to death $(n=17)$. These measurements were excluded from analyses. Data for participants with parts of questionnaires missing were imputed through multiple imputation. Nine additional participants were excluded because they had an outlier in total costs, leaving 390 participants for the primary analyses.

Table 1 shows the baseline characteristics of the people with dementia and the informal caregivers. The mean age of the people with dementia was 77 years, of whom 53\% were female. Mean age of the informal caregivers was 67 years, of whom $67 \%$ were female. Of these 390 participants, 41 were not living in their own home at 6 months and at 12 months follow up, 49 participants were not living at their own home (i.e., intermediate forms of accommodation, dementia-specific residential accommodation, long-term institutional care or other).

Descriptive statistics of the person with dementia EQ-5D-5L, as rated by the informal caregiver, at baseline are shown in Fig. 1. Between 3.6\% and 10.5\% showed severe problems and between $0.3 \%$ and $4.6 \%$ showed extreme problems.

Percentages of needs and transitions over time are displayed in Fig. 2a and b.

The largest proportion of rater reported needs that remained unmet were found for "daytime activities" and "company".

\section{Unmet need predictors of costs}

Total annual costs were not significantly related to the sum of unmet needs (step 1). The following CANE items were significant in the univariate analysis using costs as outcome and were selected for the costs model (Supplementary Table 2) in the second step of the analysis: looking after the home, daytime activities, mobility/falls, information, accidental self-harm, company and benefits. The final model (step 2) showed that costs were significantly different for "company" only (Table 2; Supplementary Table 3), where having an unmet need was associated with lower costs $(€-2,709, p=0.012)$ compared to having a met need. Results (not displayed) showed that having no need for all items, except "information", led to lower costs compared to having a met need. 
Table 1

Characteristics of the person with dementia and informal caregiver at baseline $(n=390)$

\begin{tabular}{lcc}
\hline Characteristic & Mean (SD), range or $n(\%)$ & $\%$ missing \\
\hline Person with dementia & & \\
Age & $77.4(7.8), 47-95$ & $0 \%$ \\
Gender, male $n(\%)$ & $182(47)$ & $0 \%$ \\
Years of education & $10(4.6), 0-25$ & $<1 \%$ \\
PSMS (0-6) & $3.7(1.8), 0-6$ & $<1 \%$ \\
IADL (0-8) & $3.5(2), 0-8$ & $<1 \%$ \\
MMSE total (0-30) & $19(5), 3-30$ & $<\%$ \\
NPI-Q total (0-30) & $7.5(5.6), 0-30$ & $<1 \%$ \\
EQ-5D-5L, person with dementia proxy scored utility* & $0.72(0.20),-0.074-1$ & $3 \%$ \\
ICECAP-O, proxy scored utility* & $0.70(0.16), 0.15-0.98$ & $2 \%$ \\
Number of unmet needs (rater) & $1.7(2) 0-11$ & $0 \%$ \\
Informal caregiver & & $0 \%$ \\
Age & $66.5(13.3), 28-92$ & $<1 \%$ \\
Gender, male $n(\%)$ & $130(33)$ & $0 \%$ \\
Years of education & $12(4.4), 0-24$ & \\
Relationship, $n(\%)$ & & \\
$\quad$ Spouse & $241(62)$ & \\
$\quad$ Partner & $13(3)$ & $4 \%$ \\
Son/daughter & $114(29)$ & $<1 \%$ \\
$\quad$ Other (e.g. friend) & $22(6)$ & \\
CarerQoL, utility & $284(73)$ & \\
Lives together with person with dementia $n(\%)$ & $0.76(0.17), 0.106-1.002$ & \\
\hline
\end{tabular}

PSMS, Physical Self Maintenance Scale; IADL, Instrumental activities of daily living; MMSE, MiniMental State Examination; NPI, Neuropsychiatric Inventory. *using UK tariff.

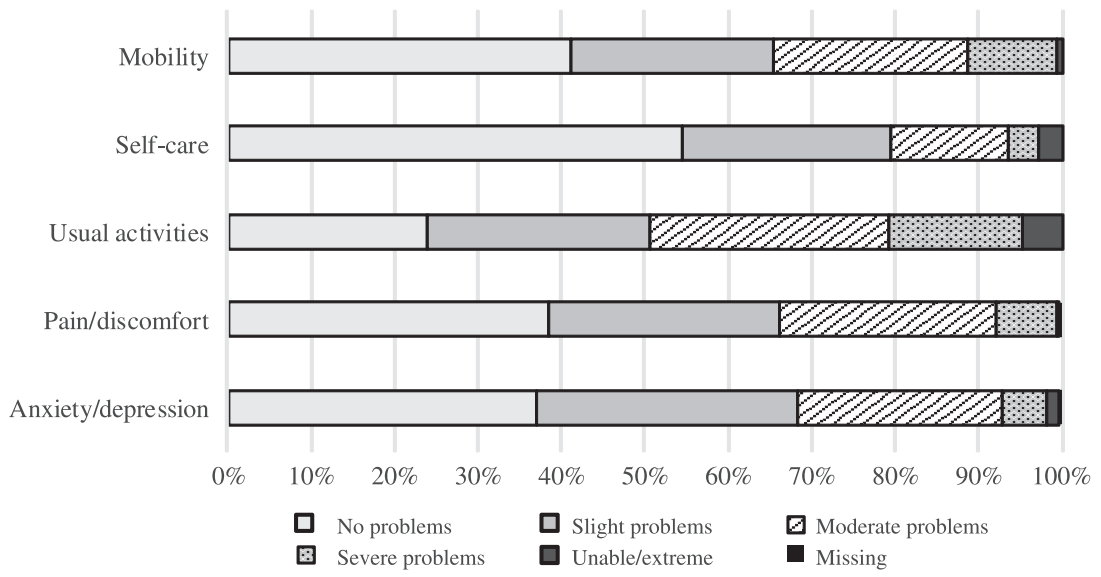

Fig. 1. Baseline percentages of proxy reported patient quality of life for each dimension (EQ-5D-5L; $n=390)$.

\section{Unmet need predictors of $H R Q o L$}

The sum of unmet needs (step 1) was significantly associated with HRQoL $(p<0.001)$, reflecting a lower HRQoL $(-0.017)$ for each additional unmet need (also see Supplementary Figure 1). The following CANE items were significant in the univariate analysis using HRQoL as outcome: looking after the home, daytime activities, mobility/falls, psychotic symptoms, psychological distress, accidental selfharm, company and benefits. The final model showed that having an unmet need on "mobility/falls" was significantly related to a lower HRQoL $(-0.054$, $p=0.006$ ) compared with having a met need (Table 3; Supplementary Table 4). Having no need was significantly related to a higher HRQoL compared to having a met need on all the items in final model.

\section{Sensitivity analysis}

Sensitivity analysis allows us to see how sensitive our results are to the assumptions of our models 
a
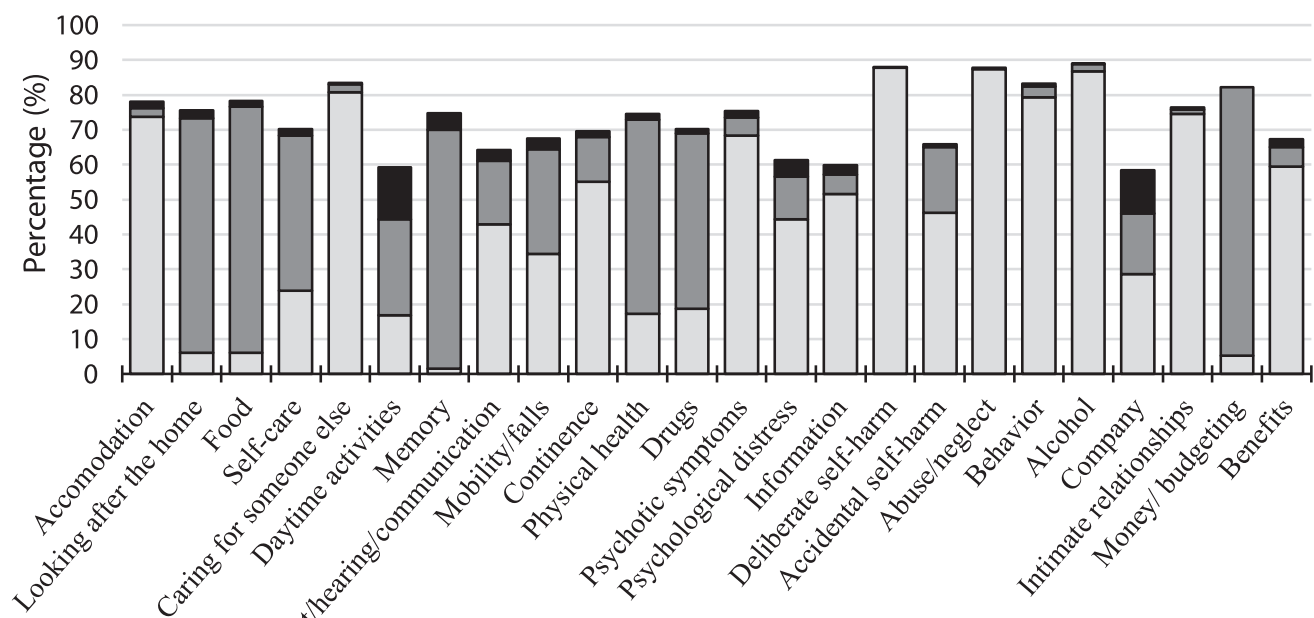

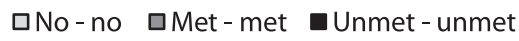

b
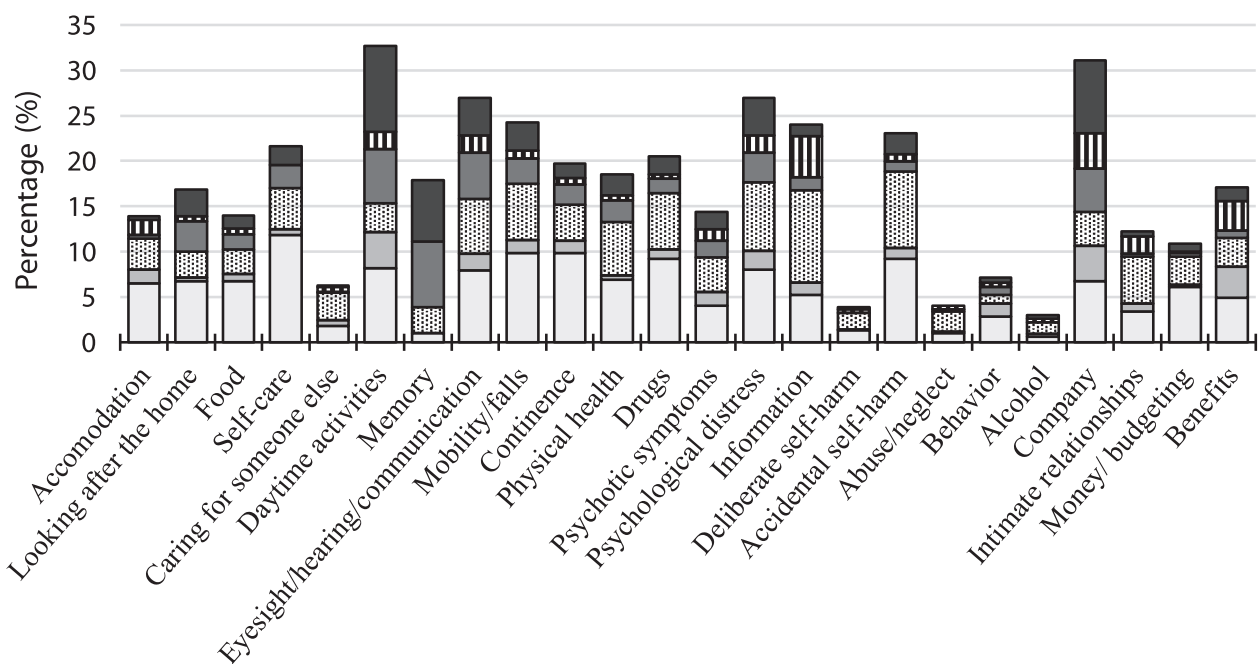

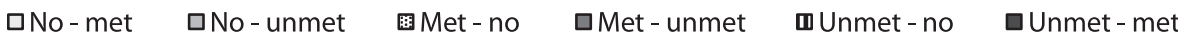

Fig. 2. a. Percentage of need status on all CANE items between baseline, 6 months and 12 months follow up for those participants in whom no change of needs was observed. Missing transitions are not displayed. b. Percentage of need status transitions on all CANE items between baseline, 6 months and 12 months follow up for those participants in whom a change of needs was observed. Missing transitions are not displayed.

[23]. Inclusion of the nine participants with outliers (costs ranging between $€ 121,238$ and $€ 269,845$ ) on total costs showed the same results for HRQoL, meaning the same CANE items remained significant after the backward procedure. Using costs as outcome showed some deviation, i.e., "Company", was no longer significant. There was a significant positive correlation between ICECAP-O and EQ-5D5L utilities at baseline, $r=0.47 ; n=377 ; p<0.001$, indicating weak to medium correlation. When using ICECAP-O scores instead of EQ-5D-5L scores, "psychological distress" instead of "mobility/falls" was significant (Supplementary Table 5). Including region as a fixed factor did not change the results. Finally, the fixed effects model using costs and HRQoL change scores between baseline and 12 months follow-up showed no significant results for either of the two outcomes. 
Table 2

Multivariate results of final model using costs as outcome $(n=390)^{1}$

\begin{tabular}{lcccc}
\hline CANE item & \multicolumn{4}{c}{ Unmet versus met need* } \\
\cline { 2 - 5 } & Coefficient ${ }^{2}$ & $\begin{array}{c}\text { Standard } \\
\text { error }\end{array}$ & $\begin{array}{c}\text { Back } \\
\text { transformed } \\
\text { coefficient }^{3}(€)\end{array}$ & $p$ \\
\hline Looking after the home & -0.027 & 0.080 & -564 & 0.737 \\
Daytime activities & -0.026 & 0.052 & -547 & 0.618 \\
Mobility/falls & 0.003 & 0.074 & 70 & 0.965 \\
Information & -0.113 & 0.075 & $-2,288$ & 0.128 \\
Company & $\mathbf{- 0 . 1 3 6}$ & $\mathbf{0 . 0 5 4}$ & $\mathbf{- 2 , 7 0 9}$ & $\mathbf{0 . 0 1 2}$ \\
Benefits & -0.033 & 0.079 & -694 & 0.675 \\
\hline
\end{tabular}

In bold: significance $<0.05 ;{ }^{*}$ No need versus met need not displayed in table; constant is 9.968. ${ }^{1}$ Table only displaying dummy pairs shown to significantly improve the model. ${ }^{2}$ this is the estimated (rounded) coefficient of the model fitted to the log transformed costs outcome.

${ }^{3}$ the coefficient was back-transformed using the following formula:

$\left(\exp \left(\right.\right.$ constant $\left.\left.+1 * \mathrm{CANE}_{\text {dummy } 2}+0 * \mathrm{CANE}_{\text {dummy } 3}\right)-\mathrm{a}\right)$

$-\left(\exp \left(\right.\right.$ constant $\left.\left.+1 * \mathrm{CANE}_{\text {dummy } 2}+0 * \mathrm{CANE}_{\text {dummy } 3}\right)-\mathrm{a}\right){ }^{.}$

Constant $=$ beta coefficient of the constant of the regression model. $\mathrm{CANE}_{\mathrm{dummy} 2}=$ beta coefficient for the dummy reflecting the presence of an unmet need. $\mathrm{CANE}_{\mathrm{dummy} 3}=$ beta coefficient for the dummy reflecting the presence of no need. $a=2186$, which reflects the correction factor.

Table 3

Multivariate results of final model using quality of life as outcome $(n=390)^{1}$

\begin{tabular}{lccc}
\hline CANE item & \multicolumn{3}{c}{ Unmet versus met need } \\
\cline { 2 - 4 } & Coefficient & Standard error & $p$ \\
\hline Looking after the home & -0.005 & 0.022 & 0.831 \\
Daytime activities & -0.003 & 0.012 & 0.812 \\
Mobility/falls & $\mathbf{- 0 . 0 5 4}$ & $\mathbf{0 . 0 2 0}$ & $\mathbf{0 . 0 0 6}$ \\
Psychotic symptoms & -0.019 & 0.024 & 0.428 \\
Psychological distress & -0.015 & 0.018 & 0.405 \\
Benefits & 0.030 & 0.021 & 0.162 \\
\hline
\end{tabular}

In bold: significance $<0.05$; No need versus met need not displayed in table;

${ }^{1}$ Table only displaying dummy pairs shown to significantly improve the model.

\section{Post hoc analysis}

A post hoc analysis (Supplementary Table 6.1 and 6.2) was carried out to examine whether consequential care could be identified when splitting total care costs into informal care- and formal costs (nontransformed), using the same backwards procedure on selection of CANE items. Results showed no significant cost differences when informal care costs and formal care costs were used as the outcome of interest.

\section{DISCUSSION}

We explored predictors of cost and health-related quality of life among people living with dementia. Only a weak association was found between unmet needs and 1-year total care costs resulting in lower costs. HRQoL was lower for those with an unmet need on the CANE item "mobility/falls" and also decreased with an increasing number of unmet needs.
It was expected that untimely access to care would lead to higher costs compared to timely access, especially in terms of costs related to informal care. Neither primary- nor sensitivity and post-hoc analyses confirmed this expectation. CANE item "Company" was significantly related with lower care costs when experiencing an unmet need. However, after sensitivity analysis, this association did not hold and therefore was considered not robust.

These results could suggest that having a met need indicates most likely that the need is being met by formal care, causing immediate higher costs that are not counterbalanced by the savings due to preventing consequential care. Another explanation might be that consequential care costs occur over a longer time period. For example, if the most common response to an unmet need for company is day care, then in the short-term, while the need is unmet, there will be a cost-saving related to not providing day care. On the longer term, however, it is possible that lack of 
company and social contact could turn into isolation and self-neglect. Although we adjusted for participant, country, and region in our models, it is possible that differences between countries and regional differences within countries regarding care use influences how unmet needs are addressed and could influence the association between unmet needs and care costs.

An unmet need does not necessarily indicate a situation in which no formal care at all is provided. A need could have been met by informal, rather than formal care. The fact that total costs did not significantly differ between unmet and met needs could indicate that formal care was provided, but that the level of care was considered insufficient or not appropriate to meet the need. In other words, access to care could be realized already [24]. van der Roest et al. [25] also showed that, although formal care was delivered, needs were still reported as unmet. Patrick and Peach [26] made a further distinction between under-met needs (needs that are partially satisfied) and unmet needs (needs that are not satisfied at all). In the current study such a distinction was not made, although this kind of distinction could lead to possible cost differences. Additionally, in some CANE areas several unmet needs could exist (e.g., physical health). However, the instrument records only one, making a specific distinction not possible.

As expected, our results showed a negative association between the amount of unmet needs and HRQoL, which is supported by previous studies [8-10]. In the current study, we mainly focused on health-related outcomes, since these are considered to be important outcomes in health-economic studies and evaluations. However, it is possible that this resulted in an underestimation of other QoL domains. Therefore, the ICECAP-O was used as complementary instrument. As our correlation analysis showed, ICECAP-O and EQ-5D-5L were weak to moderately correlated, confirming the potential of complementing each other. This was also stated by Franklin et al. [22], found in a validation study by Makai et al. [27] and recommended to use both alongside each other when performing evaluations of interventions in older people [28]. When looking at the specific CANE items, "mobility/falls" was significantly associated with a lower QoL measured by the EQ-5D and "psychological distress" was significantly associated with a lower QoL measured by the ICECAP-O. This is possibly related to the specific scale's sensitivity to the needs domain as mobility is an item in the EQ-5D, and psychological distress might be closer to the concept of capabilities measured by the ICECAPO. Nevertheless, needs on the social domain would have been expected to be associated with HRQoL as this was found to be an important domain for older people [29]. Since HRQoL (EQ-5D-5L) is scored by the informal caregiver, we included caregiver characteristics to final model to examine whether this would influence the results. The results (Supplementary Table 7) showed that adjusting for age, gender, living together, and care related QoL, did not alter the results regarding significance and direction of effects. Although not within our scope of the current study, the analysis showed that other (informal caregiver related) factors were also associated with HRQoL of the person with dementia as scored by the informal caregiver.

Livingston et al. [30] stressed the need of individualizing dementia care by tailoring care to individual and cultural needs. Our results furthermore imply that HRQoL is increasingly affected when unmet needs accumulate, showing the importance of also taking into account the number of unmet needs when considering an individual's situation.

Our study was subject to some limitations. First, the one-year follow-up can be considered too short to pick up the longer-term impact of unmet needs. Second, although the sample was meant to be typical, generalization of the results may be limited because the cohort consisted of a convenience sample. Third, reasons for not considering formal support might be similar to reasons for not participating in a scientific study that evaluates access to formal care, introducing a possible selection bias toward persons who are in a stable situation regarding their needs and received care. Fourth, as supported by Fig. 2a and $\mathrm{b}$, the proportion of transitions in needs was lower than expected, possibly resulting in too small a variation to potentially show an association with HRQoL and costs.

A further important consideration when interpreting these results was that we did not correct for multiple testing as the secondary analyses with ICECAP-O as an outcome was purely for explorative purposes.

\section{Recommendations for research, practice, and policy}

Identifying, managing, and preventing unmet needs of people with dementia living at home is important as our research has indicated this as a potential pathway to improve HRQoL. The long-term 
impact of untimely access to care remains unknown, which will be part of an extension of the Actifcare cohort for 5 years. The results showed that the number of unmet needs has an impact on HRQoL. As individual and cultural differences in needs exist, it would be of interest to examine whether need profiles exist, i.e., whether clusters of people could be identified on the basis of their combinations of needs and whether such clusters are associated with differing HRQoL.

\section{ACKNOWLEDGMENTS}

The authors want to thank everyone who participated in the study and everyone involved in the data collection.

This is an EU Joint Programme-Neurodegenerative Disease Research (JPND) project. The project is supported through the following funding organizations under the aegis of JPND-www.jpnd.eu. Germany, Ministry of Education and Research, Ireland, Health research board, Italy, Ministry of Health, the Netherlands, The Netherlands organization for Health Research and Development, Sweden, The Swedish Research Council for Health, Working Life and Welfare, Norway, The Research Council of Norway, Portugal, Foundation for Science and Technology (Fundação para a Ciência e Tecnologia, FCT: JPND-HC/0001/2012), United Kingdom, Economic and Social Research Council.

Authors' disclosures available online (https:// www.j-alz.com/manuscript-disclosures/18-0531r1).

\section{SUPPLEMENTARY MATERIAL}

The supplementary material is available in the electronic version of this article: http://dx.doi.org/ 10.3233/JAD-180531.

\section{REFERENCES}

[1] Wimo A, Guerchet M, Ali GC, Wu YT, Prina AM, Winblad B, Jonsson L, Liu Z, Prince M (2017) The worldwide costs of dementia 2015 and comparisons with 2010. Alzheimers Dement 13, 1-7.

[2] Lim J, Goh J, Chionh HL, Yap P (2012) Why do patients and their families not use services for dementia? Perspectives from a developed Asian country. Int Psychogeriatr 24, 15711580.

[3] Gaugler JE, Kane RL, Kane RA, Newcomer R (2005) Early community-based service utilization and its effects on institutionalization in dementia caregiving. Gerontologist 45, $177-185$
[4] Bieber A, Stephan A, Verbeek H, Verhey F, Kerpershoek L, Wolfs C, de Vugt M, Woods RT, Rosvik J, Selbaek G, Sjolund BM, Wimo A, Hopper L, Irving K, Marques MJ, Goncalves-Pereira M, Portolani E, Zanetti O, Meyer G (2018) Access to community care for people with dementia and their informal carers: Case vignettes for a European comparison of structures and common pathways to formal care. Z Gerontol Geriatr 51, 530-536.

[5] Gulliford M, Figueroa-Munoz J, Morgan M, Hughes D, Gibson B, Beech R, Hudson M (2002) What does 'access to health care' mean? J Health Serv Res Policy 7, 186-188.

[6] Roelands M, Van Oost P, Depoorter A (2008) Service use in family caregivers of persons with dementia in Belgium: Psychological and social factors. Health Soc Care Соттиnity 16, 42-53.

[7] Morhardt D (2011) Accessing community-based and long-term care services: Challenges facing persons with frontotemporal dementia and their families. J Mol Neurosci 45, 737-741.

[8] Miranda-Castillo C, Woods B, Galboda K, Oomman S, Olojugba C, Orrell M (2010) Unmet needs, quality of life and support networks of people with dementia living at home. Health Qual Life Outcomes 8, 132.

[9] Kerpershoek L, de Vugt M, Wolfs C, Woods B, Jelley H, Orrell M, Stephan A, Bieber A, Meyer G, Selbaek G, Handels R, Wimo A, Hopper L, Irving K, Marques M, Goncalves-Pereira M, Portolani E, Zanetti O, Verhey F, Actifcare Consortium (2018) Needs and quality of life of people with middle-stage dementia and their family carers from the European Actifcare study. When informal care alone may not suffice. Aging Ment Health 22, 897-902.

[10] Millenaar J, Hvidsten L, de Vugt ME, Engedal K, Selbaek G, Wyller TB, Johannessen A, Haugen PK, Bakker C, van Vliet D, Koopmans RT, Verhey FR, Kersten H (2017) Determinants of quality of life in young onset dementia - results from a European multicenter assessment. Aging Ment Health 21, 24-30.

[11] Gaugler JE, Kane RL, Kane RA, Newcomer R (2005) Unmet care needs and key outcomes in dementia. $J \mathrm{Am}$ Geriatr Soc 53, 2098-2105.

[12] Rudolph JL, Zanin NM, Jones RN, Marcantonio ER, Fong TG, Yang FM, Yap L, Inouye SK (2010) Hospitalization in community-dwelling persons with Alzheimer's disease: Frequency and causes. J Am Geriatr Soc 58, 1542-1548.

[13] Kerpershoek L, de Vugt M, Wolfs C, Jelley H, Orrell M, Woods B, Stephan A, Bieber A, Meyer G, Engedal K, Selbaek G, Handels R, Wimo A, Hopper L, Irving K, Marques M, Goncalves-Pereira M, Portolani E, Zanetti O, Verhey F (2016) Erratum to: Access to timely formal dementia care in Europe: Protocol of the Actifcare (ACcess to Timely Formal Care) study. BMC Health Serv Res 16, 620.

[14] Reynolds T, Thornicroft G, Abas M, Woods B, Hoe J, Leese M, Orrell M (2000) Camberwell Assessment of Need for the Elderly (CANE). Development, validity and reliability. $\mathrm{Br}$ J Psychiatry 176, 444-452.

[15] Herdman M, Gudex C, Lloyd A, Janssen M, Kind P, Parkin D, Bonsel G, Badia X (2011) Development and preliminary testing of the new five-level version of EQ-5D (EQ-5D-5L). Qual Life Res 20, 1727-1736.

[16] Devlin NJ, Shah KK, Feng Y, Mulhern B, van Hout B (2018) Valuing health-related quality of life: An EQ-5D-5L value set for England. Health Econ 27, 7-22. 
[17] Feng Y, Devlin NJ, Shah KK, Mulhern B, van Hout B (2018) New methods for modelling EQ-5D-5L value sets: An application to English data. Health Econ 27, 23-38.

[18] Wimo A, Gustavsson A, Jonsson L, Winblad B, Hsu MA, Gannon B (2013) Application of Resource Utilization in Dementia (RUD) instrument in a global setting. Alzheimers Dement 9, 429-435.e417.

[19] Johannesson M, Borgquist L, Jonsson B, Rastam L (1991) The costs of treating hypertension-an analysis of different cut-off points. Health Policy 18, 141-150.

[20] Handels RLH, Sköldunger A, Bieber A, Tudor Edwards, Gonçalves-Pereira M, Hopper L, Irving K, Jelly H, Kerpershoek L, Marques MJ, Meyer G, Michelet M, Portolani E, Røsvik J, Selbaek G, Stephan A, de Vugt M, Wolfs C, Woods B, Zanetti O, Verhey F, Wimo A, Actifcare consortium (2018) Quality of life, care resource use, and costs of dementia in 8 European countries in a cross-sectional cohort of the Actifcare study. J Alzheimers Dis 66(3), 1027-1040.

[21] Coast J, Flynn TN, Natarajan L, Sproston K, Lewis J, Louviere JJ, Peters TJ (2008) Valuing the ICECAP capability index for older people. Soc Sci Med 67, 874-882.

[22] Franklin M, Payne K, Elliott RA (2018) Quantifying the relationship between capability and health in older people: Can't map, won't map. Med Decis Making 38, 79-94.

[23] Drummond MF, Sculpher MJ, Claxton K, Stoddart GL, Torrance GW (2015) Methods for the economic evaluation of health care programmes, Oxford University Press.

[24] Andersen RM (1995) Revisiting the behavioral model and access to medical care: Does it matter? J Health Soc Behav 36, 1-10.
[25] van der Roest HG, Meiland FJ, Comijs HC, Derksen E, Jansen AP, van Hout HP, Jonker C, Droes RM (2009) What do community-dwelling people with dementia need? A survey of those who are known to care and welfare services. Int Psychogeriatr 21, 949-965.

[26] Patrick DL, Peach H (1989) Disablement in the community, Oxford University Press, USA.

[27] Makai P, Brouwer WB, Koopmanschap MA, Nieboer AP (2012) Capabilities and quality of life in Dutch psychogeriatric nursing homes: An exploratory study using a proxy version of the ICECAP-O. Qual Life Res 21, 801-812.

[28] Makai P, Brouwer WB, Koopmanschap MA, Stolk EA, Nieboer AP (2014) Quality of life instruments for economic evaluations in health and social care for older people: A systematic review. Soc Sci Med 102, 83-93.

[29] Bruggencate TT, Luijkx KG, Sturm J (2018) Social needs of older people: A systematic literature review. Ageing Soc 38, 1745-1770.

[30] Livingston G, Sommerlad A, Orgeta V, Costafreda SG, Huntley J, Ames D, Ballard C, Banerjee S, Burns A, CohenMansfield J, Cooper C, Fox N, Gitlin LN, Howard R, Kales HC, Larson EB, Ritchie K, Rockwood K, Sampson EL, Samus Q, Schneider LS, Selbaek G, Teri L, Mukadam N (2017) Dementia prevention, intervention, and care. Lancet 390, 2673-2734.

[31] Luengo-Fernandez R, Leal J, Gray AM (2011) Cost of dementia in the pre-enlargement countries of the European Union. J Alzheimers Dis 27, 187-196. 